\title{
Aorticopulmonary Paraganglioma
}

National Cancer Institute

\section{Source}

National Cancer Institute. Aorticopulmonary Paraganglioma. NCI Thesaurus. Code C4218.

A benign or malignant extra-adrenal parasympathetic paragang lioma that arises from paraganglia adjacent to the base of the heart and great vessels. 